\title{
Thermal Decomposition of Silver Acetate: Physico-Geometrical Kinetic Features and Formation of Silver Nanoparticles
}

Masayoshi Nakano, Takayuki Fujiwara, and Nobuyoshi Koga*

Department of Science Education, Graduate School of Education, Hiroshima University,

1-1-1 Kagamiyama, Higashi-Hiroshima 739-8524, Japan

*nkoga@hiroshima-u.ac.jp

\section{S1. Sample Characterization}
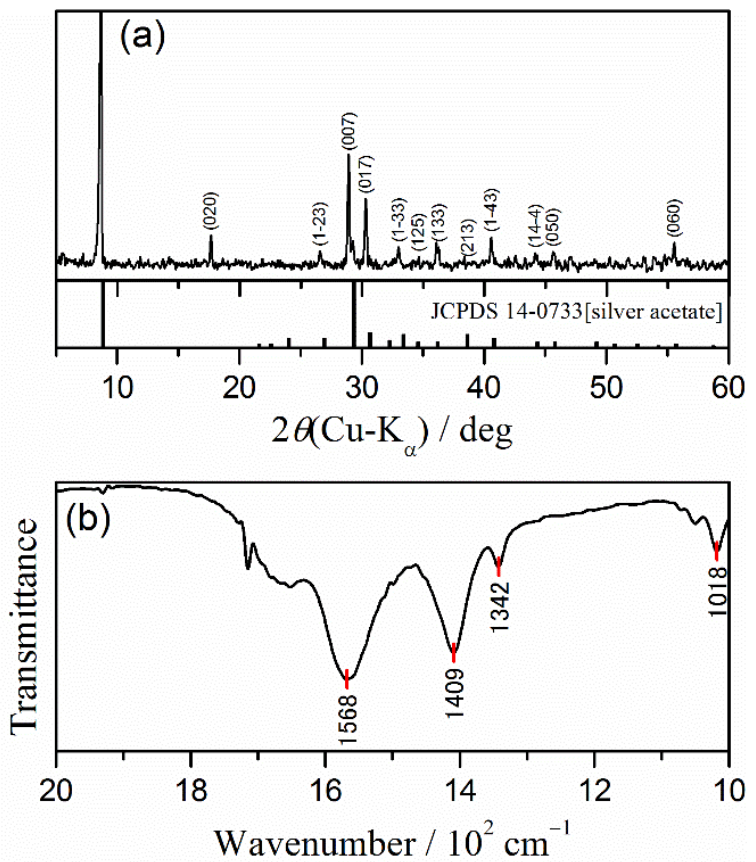

Figure S1. (a) XRD pattern and (b) FT-IR spectrum of asreceived silver acetate sample.

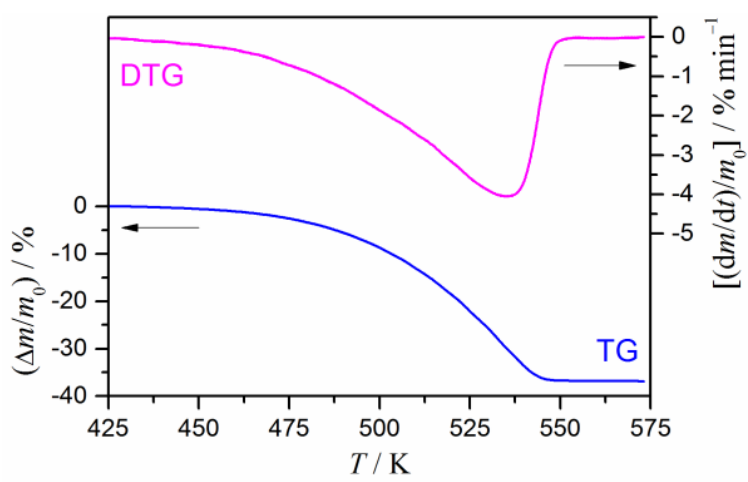

Figure S2. Typical TG-DTG curves for thermal decomposition of as-received silver acetate sample $\left(m_{0}=1.96 \mathrm{mg}\right)$ at a $\beta=5 \mathrm{~K}$ $\min ^{-1}$ in flowing $\mathrm{N}_{2}\left(80 \mathrm{~cm}^{3} \mathrm{~min}^{-1}\right)$.
S2. Thermal Decomposition Process

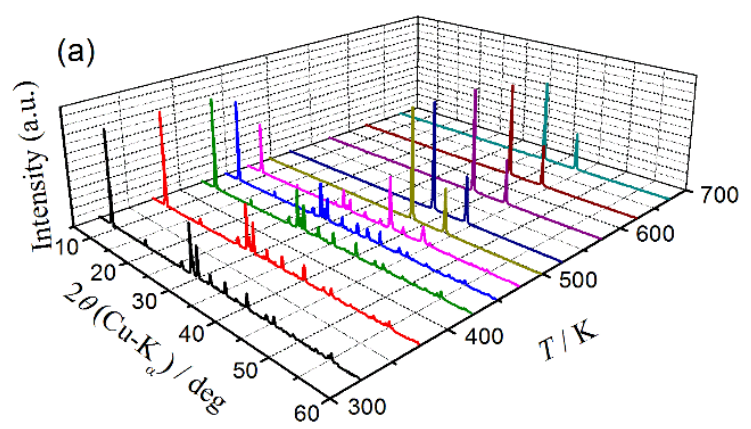

(b)

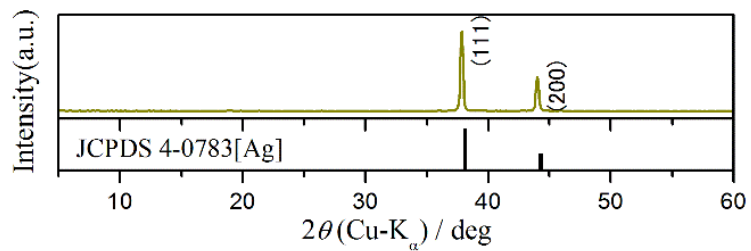

Figure S3. Changes in XRD patterns during stepwise isothermal heating of silver acetate in flowing $\mathrm{N}_{2}\left(100 \mathrm{~cm}^{3} \mathrm{~min}^{-1}\right)$ : (a) changes in XRD patterns with temperature and (b) XRD pattern of solid product. 

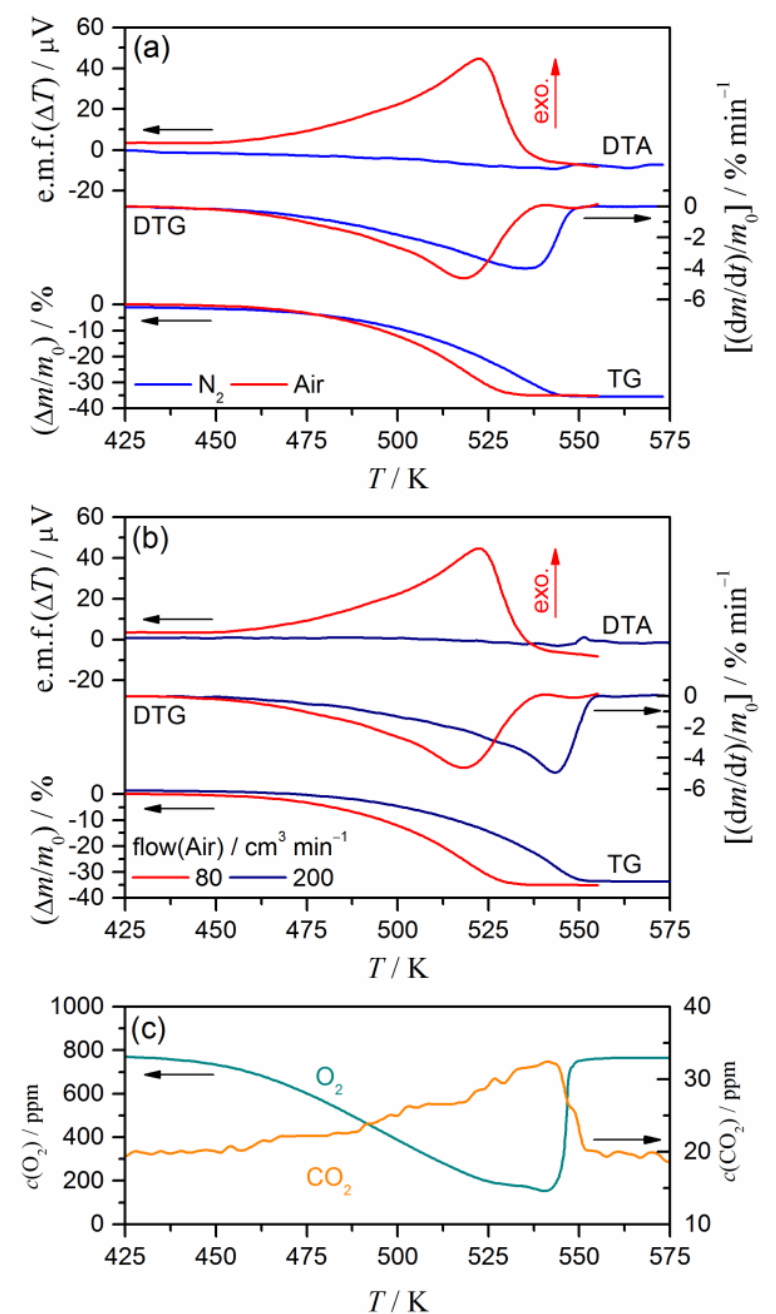

Figure S4. Influences of atmospheric conditions on TG-DTGDTA curves for thermal decomposition of silver acetate $\left(m_{0}=\right.$ $2.02 \pm 0.04 \mathrm{mg}$ ) at $\beta=5 \mathrm{~K} \mathrm{~min}^{-1}$ : (a) comparison of curves obtained in flowing $\mathrm{N}_{2}$ and air $\left(80 \mathrm{~cm}^{3} \mathrm{~min}^{-1}\right)$, (b) comparison of curves obtained in flowing air at flow rates of 80 and $200 \mathrm{~cm}^{3}$ $\min ^{-1}$, and (c) curves obtained in flowing $\mathrm{N}_{2}$-air mixture $\left(c\left(\mathrm{O}_{2}\right)\right.$ $=800 \mathrm{ppm})$ at rate of $500 \mathrm{~cm}^{3} \mathrm{~min}^{-1}$ and changes in concentrations of $\mathrm{O}_{2}$ and $\mathrm{CO}_{2}$ in outlet gas during reaction.
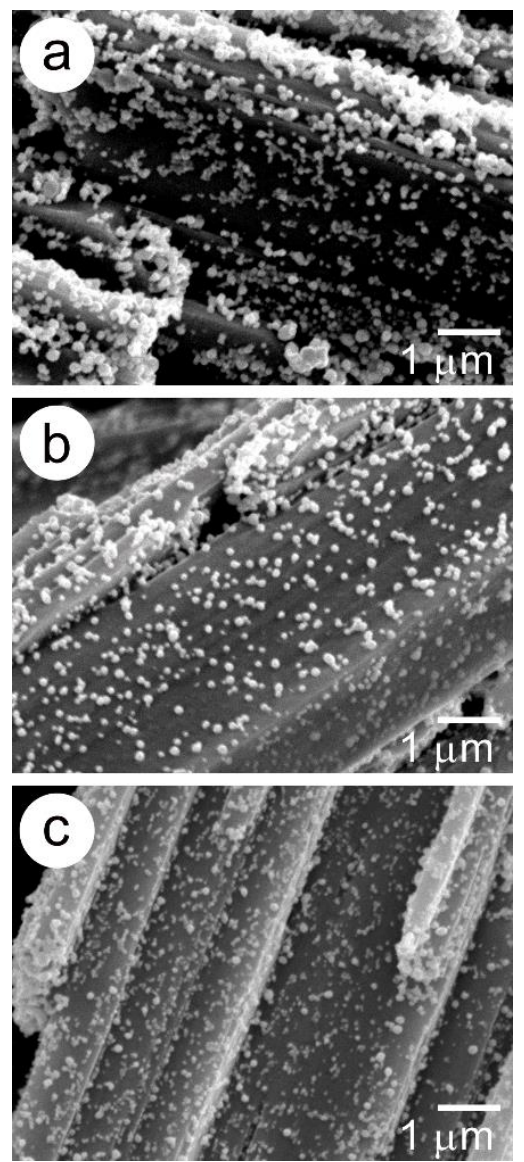

Figure S5. SEM images of partially decomposed samples $(\alpha=$ 0.3 ) obtained by heating under isothermal conditions in flowing $\mathrm{N}_{2}\left(80 \mathrm{~cm}^{3} \mathrm{~min}^{-1}\right)$ : (a) $438 \mathrm{~K}$, (b) $453 \mathrm{~K}$, and (c) $468 \mathrm{~K}$.

\section{S3. Impact of Atmospheric Water Vapor on the Kinetics}

Table S1. Initial kinetic parameters for the kinetic deconvolution analysis of thermal decomposition of silver acetate in flowing $\mathrm{N}_{2}-$ $\mathrm{H}_{2} \mathrm{O}$ with controlled $p\left(\mathrm{H}_{2} \mathrm{O}\right)$

\begin{tabular}{cccccccc}
\hline \multirow{2}{*}{$p\left(\mathrm{H}_{2} \mathrm{O}\right) / \mathrm{kPa}$} & $i$ & $c_{i}$ & $E_{\mathrm{a}, i} / \mathrm{kJ} \mathrm{mol}^{-1, \mathrm{a}}$ & $A_{i} / \mathrm{s}^{-1}$ & \multicolumn{2}{c}{$\mathrm{SB}(m, n, p)$} \\
\cline { 5 - 7 } & & & & & $m_{i}$ & $n_{i}$ & $p_{i}$ \\
\hline 0.2 & 1 & 0.20 & 84.6 & $2.0 \times 10^{7}$ & 0 & 1 & 0 \\
& 2 & 0.80 & 78.1 & $5.0 \times 10^{5}$ & 0 & 1 & 0 \\
\hline 4.0 & 1 & 0.20 & 91.6 & $2.0 \times 10^{8}$ & 0 & 1 & 0 \\
& 2 & 0.80 & 85.2 & $5.0 \times 10^{6}$ & 0 & 1 & 0 \\
\hline 16.3 & 1 & 0.20 & 108.0 & $2.0 \times 10^{10}$ & 0 & 0 & 0 \\
& 2 & 0.80 & 88.3 & $2.0 \times 10^{7}$ & 0 & 1 & 0 \\
\hline
\end{tabular}

\footnotetext{
a average values at different $\alpha$ (1st step: $0.05 \leq \alpha \leq 0.10$, 2nd step: $0.20 \leq \alpha \leq 0.70)$.
} 


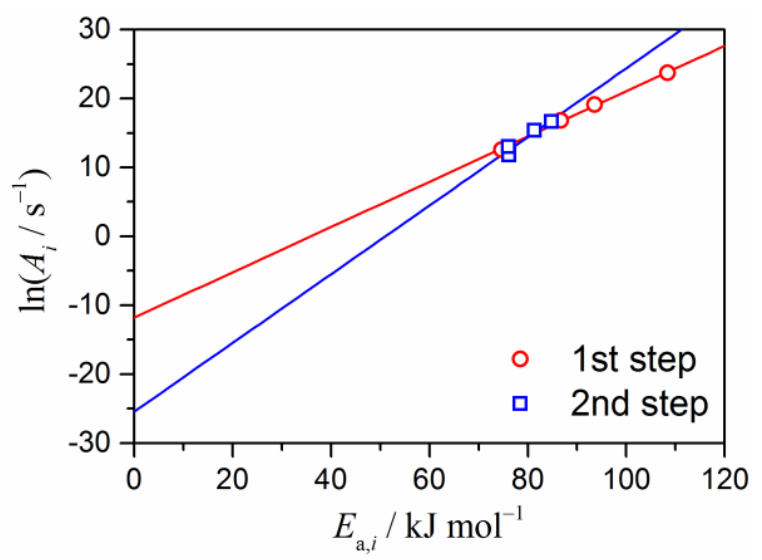

Figure S6. Mutual dependence of $E_{\mathrm{a}}$ and $\ln A$ values determined under different $p\left(\mathrm{H}_{2} \mathrm{O}\right)$.
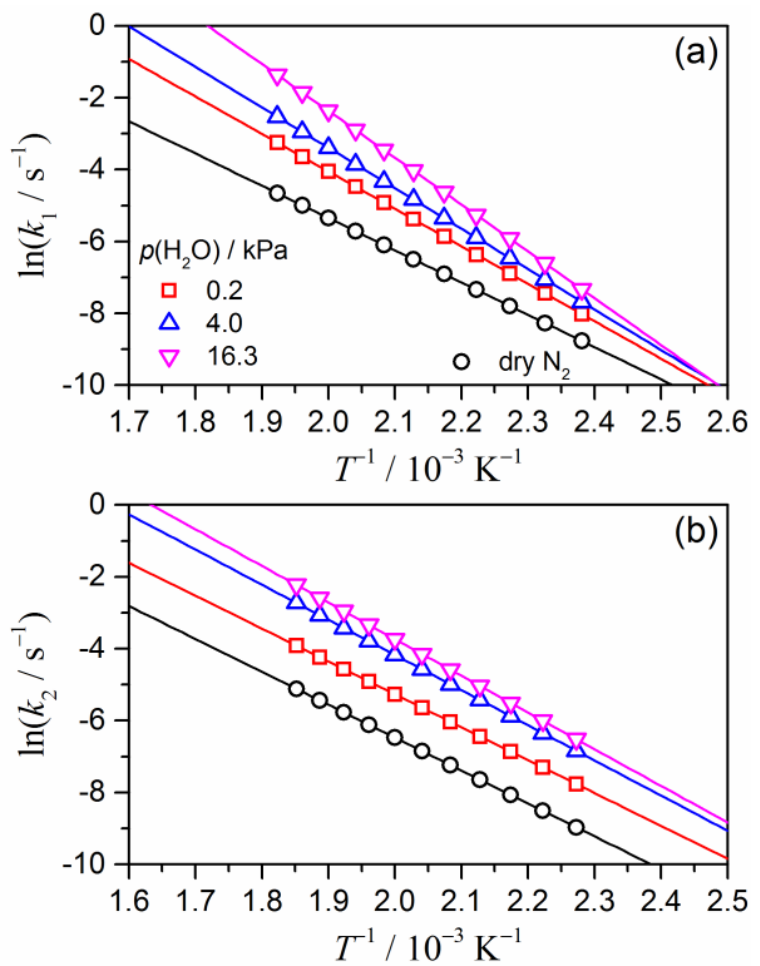

Figure S7. Comparisons of Arrhenius plots for the reactions under different $p\left(\mathrm{H}_{2} \mathrm{O}\right)$ simulated using $E_{\mathrm{a}}$ and $A$ values determined by kinetic deconvolution analysis: (a) first reaction step and (b) second reaction step. 